\title{
Efficient purification of cell culture-derived classical swine fever virus by ultrafiltration and size-exclusion chromatography
}

\author{
Ruining WANG ${ }^{1}$, Yubao ZHI ${ }^{2}$, Junqing GUO' ${ }^{2}$, Qingmei LI $^{2}$, Li WANG ${ }^{2}$, Jifei YANG ${ }^{2}$, Qianyue JIN ${ }^{2}$, \\ Yinbiao WANG ${ }^{2}$, Yanyan YANG ${ }^{2}$, Guangxu XING ${ }^{2}$, Songlin QIAO ${ }^{2}$, Mengmeng ZHAO ${ }^{1}$, Ruiguang DENG ${ }^{2}$, \\ Gaiping ZHANG (凶) ${ }^{1}$
}

\begin{abstract}
1 College of Animal Science and Veterinary Medicine, Henan Agricultural University, Zhengzhou 450002, China
2 Key Laboratory of Animal Immunology of the Ministry of Agriculture, Henan Provincial Key Laboratory of Animal Immunology, Henan Academy of Agricultural Sciences, Zhengzhou 450002, China
\end{abstract}

\begin{abstract}
Large-scale production of cell culture-based classical swine fever virus (CSFV) vaccine is hampered by the adverse reactions caused by contaminants from host cell and culture medium. Hence, we have developed an efficient method for purifying CSFV from cell-culture medium. Pure viral particles were obtained with two steps of tangential-flow filtration (TFF) and size-exclusion chromatography (SEC), and were compared with particles from ultracentrifugation by transmission electron microscopy (TEM), infectivity and recovery test, and real time fluorescent quantitative PCR (FQ-PCR). TFF concentrated the virus particles effectively with a retention rate of $98.5 \%$, and $86.2 \%$ of viral particles were obtained from the ultrafiltration retentate through a Sepharose 4 F F column on a biological liquid chromatography system. CSFV purified by TFF-SEC or ultracentrifugation were both biologically active from $1.0 \times 10^{-4.25} \mathrm{TCID}_{50} \cdot \mathrm{mL}^{-1}$ to $3.0 \times 10^{-6.25} \mathrm{TCID}_{50} \cdot \mathrm{mL}^{-1}$, but the combination of TFF and SEC produced more pure virus particles than by ultracentrifugation alone. In addition, pure CSFV particles with the expected diameter of $40-60 \mathrm{~nm}$ were roughly spherical without any visible contamination. Mice immunized with CSFV purified by TFF-SEC produced higher antibody levels compared with immunization with ultracentrifugation-purified CSFV $(P<0.05)$. The purification procedures in this study are reliable technically and feasible for purification of large volumes of viruses.
\end{abstract}

Keywords classical swine fever virus, virus purification, tangential-flow filtration, size-exclusion chromatography

Received August 1, 2015; accepted September 20, 2015

Correspondence: zhanggaiping2003@163.com

\section{Introduction}

Classical swine fever virus (CSFV) is the causative agent of classical swine fever (CSF), a highly contagious and often fatal swine disease. It is an enveloped, singlestranded RNA virus with a genome of $12.3 \mathrm{~kb}$ and belongs to the genus pestivirus, the family Flaviviridae together with bovine viral diarrhea virus (BVDV), and border disease virus ${ }^{[1]}$. Its genome consists of one large open reading frame encoding a polyprotein of 3898 amino acids which is processed into seven nonstructural proteins $(\mathrm{N}-$ pro, p7, NS2-3, NS4A, NS4B, NS5A and NS5B) and four structural proteins including a putative nucleocapsid protein $(\mathrm{C})$ and three envelope glycoproteins (E0, El and E2) ${ }^{[2,3]}$.

Currently, cell culture-based CSFV vaccines are used widely in China and many other countries to prevent and control CSFV infection ${ }^{[4]}$. However, large-scale production of cell culture-based CSFV vaccine is hampered because of the adverse reactions caused by the contaminants from host cell and cell culture medium. Purification of CSFV has routinely been achieved by cesium chloride or sucrose density gradient ultracentrifugation ${ }^{[5,6]}$, yet it was reported that the harsh force of ultracentrifugation might cause damage to viruses, especially to enveloped viruses $^{[7]}$, and bench scale gradient ultracentrifugation is unsuitable for larger scale processes ${ }^{[8]}$. The development of an effective method for purifying CSFV virus from cell culture during vaccine manufacturing remains a research priority. To overcome this, the use of ultrafiltration has become common in virus purification ${ }^{[9-14]}$; however, virus is only partially purified through ultrafiltration and other particulates in the culture medium are concentrated. More 
recently, the application of size-exclusion chromatography has been reported for purification of turkey coronavirus ${ }^{[7]}$, pseudotyped vesicular stomatitis virus ${ }^{[15]}$, moloney murine leukemia-derived retrovirus ${ }^{[16]}$, and equine influenza virus $^{[13]}$. Size-exclusion chromatography would help remove small solutes (total inclusion; most likely fetal bovine serum, amino acids and nucleotides). Hence, in this study we combined the use of ultrafiltration with sizeexclusion chromatography for the concentration and purification of CSFV and provided a promising strategy for the purification of cell culture-derived viruses.

\section{Materials and methods}

\subsection{Cell culture, virus propagation and clarification}

The virulent Shimen strain of CSFV was provided by China Institute of Veterinary Drug Control and propagated in porcine kidney cells (PK-15 cells, ATCC CCL-33). A stock solution of CSFV with $5.5 \times 10^{-4.25} \mathrm{TCID}_{50} \cdot \mathrm{mL}^{-1}$ was employed as the seed virus. After CSFV inoculation, PK-15 cells were incubated in Dulbecco's modified Eagle's medium (DMEM; Gibco, UK) containing $100 \mathrm{U} \cdot \mathrm{mL}^{-1}$ penicillin, $100 \mu \mathrm{g} \cdot \mathrm{mL}^{-1}$ streptomycin, and $2 \%$ fetal bovine serum free from bovine viral diarrhea virus and its antibody (Hyclone, Logan, Utah, USA) at $37^{\circ} \mathrm{C}$ with $5 \% \quad \mathrm{CO}_{2}$. Usually, maximum virus titers were obtained $48 \mathrm{~h}$ post-inoculation in the supernatant fluid medium, which was then pooled. Cell debris was removed by centrifugation at $11000 \times g$ for $10 \mathrm{~min}$ at $4^{\circ} \mathrm{C}$ with a Beckman Allegra 21R conventional high-speed centrifuge (Beckman Instruments Inc., Palo Alto, CA, USA). Clarified supernatant was stored at $-70^{\circ} \mathrm{C}$ and used for purification by ultracentrifugation or tangential-flow ultrafiltration (TFF).

\subsection{Ultracentrifugation}

Ultracentrifugation was carried out in a Beckman ultra- centrifuge using a SW28 rotor spinning at $50000 \times g$ for $3 \mathrm{~h}$ at $4^{\circ} \mathrm{C}$. Virus-containing precipitates were dissolved by PBS buffer, and the final volume was adjusted to achieve a 25 -fold final concentration. Virus concentrate was applied for virus detection by electron microscopy, FQ-PCR, infectivity and recovery test.

\subsection{Tangential-flow filtration}

Clarified samples were processed by tangential-flow ultrafiltration through a Minimate TFF capsule (Pall Corporation, East Hills, USA) with a Minimate TM membrane. This device is made of two parts: the upper sample cup with the membrane and the lower filtrate collection tube (Fig. 1). The membrane of this device was pre-washed twice with ultrapure water. Then, an ultrafiltration membrane cassette with $50 \mathrm{kDa}$ nominal molecular weight limit (NMWL) was employed, and the permeate was added to the reservoir and pumped through the module. The retentate was recirculated and mixed with the medium in the reservoir as feed. A 25-fold virus concentrate was harvested finally, and samples of the feed, retentate and permeate were collected at regular intervals and analyzed by FQ-PCR.

\subsection{Size-exclusion chromatography}

Concentrated CSFV from TFF was further purified by sizeexclusion chromatography (SEC) at $4^{\circ} \mathrm{C}$ through a Sepharose 4 Fast Flow column (Bio-Rad, Hercules, CA) equilibrated with $0.1 \mathrm{~mol} \cdot \mathrm{L}^{-1}$ phosphate buffer $(\mathrm{pH} 7.2)$ using a biological liquid chromatography system (BioRad, California, USA). The column was eluted with the same buffer at a flow rate of $0.3 \mathrm{~mL} \cdot \mathrm{min}^{-1}$, and $\mathrm{OD}_{280}$ absorbance of eluents was monitored continuously. Virus eluent fractions collected after SEC purification were pooled into one sample and concentrated with YM-10 Microcon Centrifugal filter device (Millipore Corporation, Billerica, USA) at $4^{\circ} \mathrm{C}$, and the final volume was adjusted to the same as the ultracentrifugation.

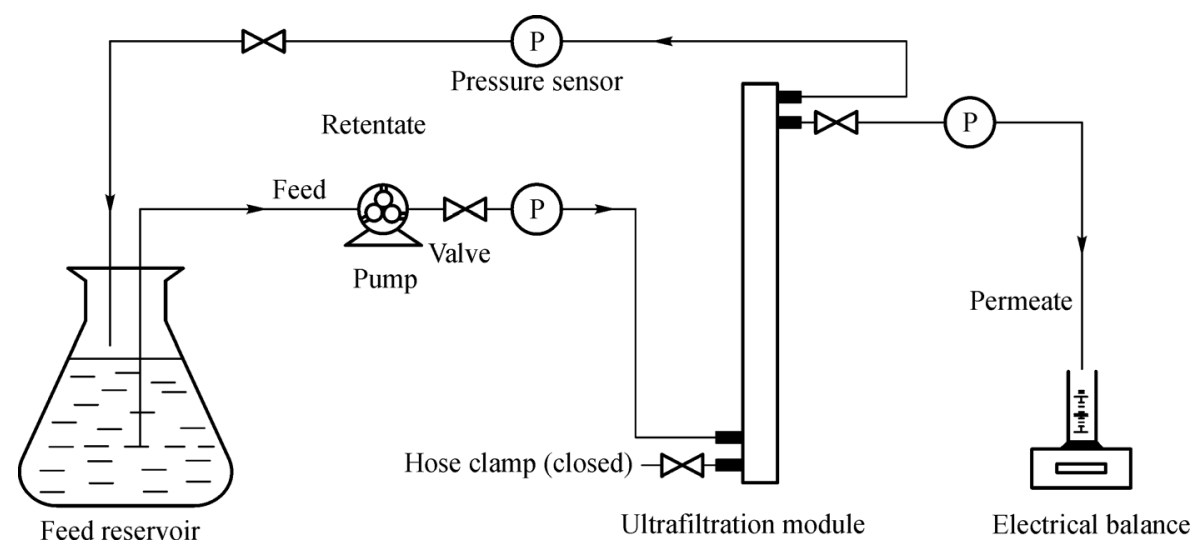

Fig. 1 Schematic representation of tangential-flow filtration 


\subsection{Virus titration}

Virus infectivity before and after purification was compared by testing $50 \%$ tissue culture infectious dose $\left(\mathrm{TCID}_{50}\right)$. TCID 50 was performed by dispensing serial 10 -fold dilutions of CSFV onto PK-15 cells growing in 96well flat bottom plates (Corning, USA). After 60 to $72 \mathrm{~h}$, immunostaining of this monolayer was observed by an indirect immunofluorescence assay (IFA), and virus titer expressed as $\mathrm{TCID}_{50} \cdot \mathrm{mL}^{-1}$ units was calculated according to Reed and Muench method ${ }^{[17]}$.

\subsection{Real-time fluorescent quantitative PCR}

FQ-PCR was used to quantitate viral particles as described $^{[18]}$. Plasmid containing the NS5A cDNA was used as an external standard for quantitation of virus particles. SYBR Green RT-PCR was performed according to the manufacturer's protocol using primers (Forward: ATTTTGCCGCATTCCAGGGC, Reverse: TCGCGTTTGGAAGTGAAGGGA). The size of the amplicon is $149 \mathrm{bp}$. Each real-time PCR reaction $(20 \mu \mathrm{L})$ contained $10 \mu \mathrm{L}$ SYBR Green Real-time PCR Master Mix (TAKARA), $0.3 \mathrm{mmol}$ gene-specific primers and $1 \mu \mathrm{L}$ standardized template cDNA. Amplification was performed using an ABI 7500 thermocycler (Life Technologies, USA) with cycles as follows: initial denaturation at $95^{\circ} \mathrm{C}$ for $5 \mathrm{~min} ; 40$ cycles of denaturation at $95^{\circ} \mathrm{C}$ for $30 \mathrm{~s}$, annealing at $56^{\circ} \mathrm{C}$ for $30 \mathrm{~s}$, extension at $72^{\circ} \mathrm{C}$ for $30 \mathrm{~s}$; and final extension at $72^{\circ} \mathrm{C}$ for $10 \mathrm{~min}$.

\subsection{Immunoblotting}

CSFV after TFF-SEC purification was applied to $12 \%$ polyacrylamide gels with sodium dodecyl sulfate (SDS). The samples were solubilized in buffer containing $62.5 \mathrm{mmol}$ Tris $-\mathrm{HCl}$, pH 6.8, $1 \%$ SDS, $10 \%$ glycerol, $0.001 \%$ bromophenol blue, and $1 \%$ 2-mercaptoethanol and boiled for $5 \mathrm{~min}$. Polypeptide bands were revealed by staining the gel with Coomassie brilliant blue G-250. For immunoblotting, viral proteins were transferred onto nitrocellulose membrane (Millipore, Bedford, MA) at $15 \mathrm{~V}$ for $1 \mathrm{~h}$. The nitrocellulose membrane was incubated overnight with gentle agitation in 5\% (w/v) skimmed milk in PBST buffer to avoid nonspecific binding. After washing in PBST, the membrane was incubated for $1 \mathrm{~h}$ at room temperature with swine anti-CSFV antiserum diluted 1:200 in PBST. After washing three times HRPconjugated goat-anti-swine IgG (Bio-Rad, Hercules, USA) was added. After incubation for $2 \mathrm{~h}$ at room temperature, the membrane was washed three times and covered with the 3,3-diaminobenzidine in the presence of $0.1 \% \mathrm{H}_{2} \mathrm{O}_{2}$. The blot was allowed to develop and the reaction was stopped by washing the membrane in distilled water.

\subsection{Electron microscopy}

The presence of intact CSFV was confirmed by transmission electron microscopy (TEM). $1 \mu \mathrm{L}$ of the purified CSFV was placed on a sheet of Parafilm. A carbonstabilized and Formvar-coated 200-mesh copper grid was floated on the drop (film side down) and allowed to adhere to the drop for $5 \mathrm{~min}$. The grid was then removed, and excess liquid was drained off by blotting the edge of the grid with a piece of clean filter paper. Then, the grid (film side down) was floated on a drop of $2 \%$ phosphotungstic acid ( $\mathrm{pH}$ 6.5) for $1 \mathrm{~min}$ and air-dried for $5 \mathrm{~min}$ after the excess phosphotungstic acid was removed as above. Several specimens were examined under a Hitachi $\mathrm{H}-$ 600-A2 transmission electron microscope at an accelerating voltage of $75 \mathrm{kV}$. The TEM images were recorded on Kodak electron microscope film 4489.

\subsection{Comparison of antibody responses}

Six-week-old BALB/c mice were randomly divided into three groups (A, B, C) with 5 mice per group. Group A was immunized four times at two-week intervals with $1.0 \times 10^{-5} \mathrm{TCID}_{50} \cdot \mathrm{mL}^{-1}$ of the inactivated purified CSFV from TFF-SEC; group B was immunized as above with inactivated ultracentrifugation-prepared CSFV; group C was injected with PBS as control. Antibody responses of each group were detected from day $0,14,28,42$ and 56 post-inoculation using ELISA. Briefly, microtiter plates were coated with E0-E2 fusion protein $\left(2 \mu \mathrm{g} \cdot \mathrm{mL}^{-1}\right)^{[19]}$ and incubated overnight at $4^{\circ} \mathrm{C}$. A blocking solution consisting of $5 \%$ skimmed milk powder in $0.01 \mathrm{~mol} \cdot \mathrm{L}^{-1} \mathrm{PBS}$ containing $0.05 \%$ Tween 20 (PBS-T) was added to each well and incubated for $1 \mathrm{~h}$ at $37^{\circ} \mathrm{C}$, then each well was washed 5 times with PBST. CSFV prepared by either TFFSEC or ultracentrifugation produced CSFV-specific antibodies $(100 \mu \mathrm{L})$ was added to each well and the plates were incubated for $1 \mathrm{~h}$ at $37^{\circ} \mathrm{C}$. After washing, the secondary goat anti-mouse immunoglobulin horseradish peroxidase (HRPO)-conjugated antibody (dilution 1:1000) was added to each well and the plate was incubated for $30 \mathrm{~min}$ at $37^{\circ} \mathrm{C}$. After washing, tetramethylene-blue (TMB, Sigma Chemicals Co.) substrate $(100 \mu \mathrm{L})$ was added to each well and incubated for $5 \mathrm{~min}$ at room temperature. The absorbance values were read at $490 \mathrm{~nm}$. Antibody titers from TFF-SEC or ultracentrifugation immunization groups were compared.

\section{Results}

\subsection{Virus concentration}

Virus stock was initially prepared from the cell culture supernatants and clarified by high-speed centrifugation. 
Clarified supernatants were concentrated and partially purified by ultrafiltration through a $50 \mathrm{kDa}$ membrane. An approximately 25 -fold concentration of virus particles was obtained with a retention about $98.5 \%$ (Fig. 2a), indicating effective retention of virus particles.

\subsection{Size-exclusion chromatography}

Two clearly separated peaks of OD280 were observed in the elution profile of size-exclusion chromatography (Fig. 2b). CSFV particles were found mainly in the first peak, and only a few viral particles appeared in the second peak. The first peak contained $86.2 \%$ of viral particles (Table 1), and the results were confirmed by SDS-PAGE and immunoblotting assay (Fig. 3). The major viral structural proteins Erns (41-44 kDa) and E1 (31-33 kDa) were detected in peak 1 , the most prominent bands in the Coomassie stained gel appeared at about $70 \mathrm{kDa}$ in peak 2 , and previous studies suggested that this band corresponds to serum albumin precursor ${ }^{[20]}$. Virus particles were very pure and only a few faint bands of the cellular proteins could be detected on Coomassie stained SDS-PAGE in peak 1. Meanwhile, this result was confirmed by immunoblotting analyses using anti-virus antibodies
(Fig. 3b), and the viral structural proteins E1, Erns and capsid protein were detected in peak 2 , while no viral proteins were detected in peak 1, which indicated the effective retention of virus particles. Meanwhile, sizeexclusion chromatography served as a buffer exchange step, replacing the impurities in the cell culture medium with PBS buffer.

\subsection{Evaluation of infectivity and recovery of virus particles}

Immunofluorescence assay was used to evaluate the infectivity of virus particles purified by the TFF-SEC method or ultracentrifugation. A strong fluorescent signal was detected $48 \mathrm{~h}$ post-inoculation with TTF-SEC or ultracentrifugation-prepared viruses (Fig. 4), indicating that CSFV virus particles prepared by both the TFF-SEC method and ultracentrifugation were biologically active, but the titer of CSFV from TFF-SEC purification was higher $\left(3.0 \times 10^{-6.25} \mathrm{TCID}_{50} \cdot \mathrm{mL}^{-1}\right)$ than that obtained from ultracentrifugation $\left(4.09 \times 10^{-5} \mathrm{TCID}_{50} \cdot \mathrm{mL}^{-1}\right)$ (Table 1). Average infectious titer of CSFV from TFF-SEC purification was from $1.0 \times 10^{-4.25}$ to $1.0 \times 10^{-6.25}$. The infectivity and recovery of the purified virus results indicated that this method was effective. (a)

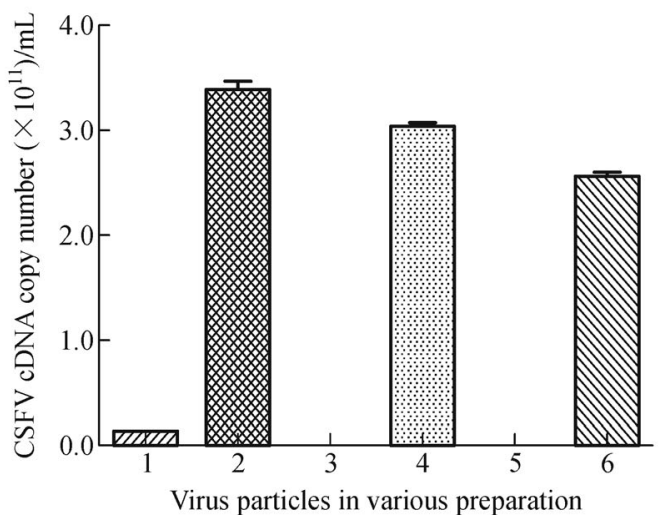

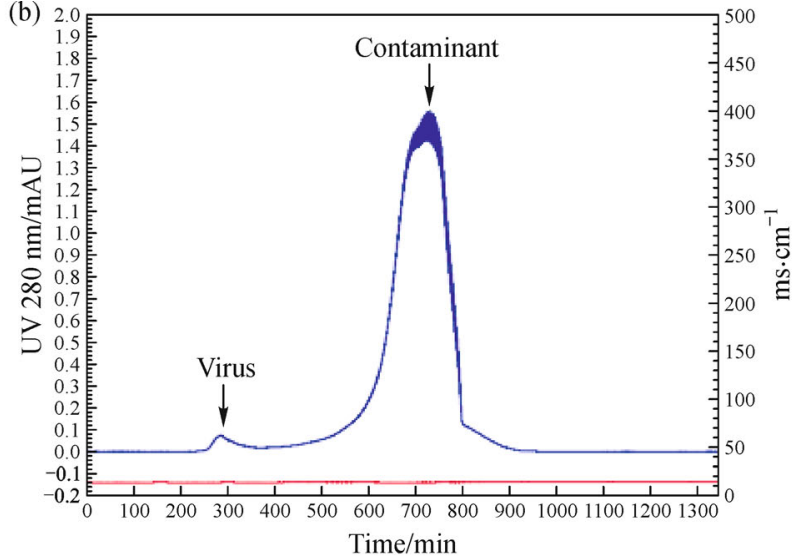

Fig. 2 Elution profile of size-exclusion chromatography and detection of CSFV by FQ-PCR. (a) The existence of CSFV in samples at various purification stages were monitored by FQ-PCR. 1, Virus stock; 2, ultrafiltration retentate; 3, ultrafiltration penetration; 4, peak 1; 5, peak 2; 6, ultracentrifugation-prepared virus; (b) TFF-concentrated CSFV was loaded onto a Sepharose 4 Fast Flow column (100 mL bed volume). Peak 1 consisted mainly of CSFV particles and peak 2 was contaminants from host cells or cell culture media.

Table 1 Monitoring of virus particles at various stages of purification

\begin{tabular}{|c|c|c|c|c|}
\hline Purification stage & Total volume $/ \mathrm{mL}$ & Particles numbers $/ \mathrm{mL}$ & Virus recovery ${ }^{\mathrm{a}} / \%$ & Virus titer $/ \mathrm{TCID}_{50} \cdot \mathrm{mL}^{-1}$ \\
\hline Virus stock & 500 & $1.36 \times 10^{10}$ & 100 & $5.5 \times 10^{-4.25}$ \\
\hline UF rententate & 20 & $3.35 \times 10^{11}$ & 98.5 & $3.4 \times 10^{-6.35}$ \\
\hline UF permeate & 485 & N/A & N/A & N/A \\
\hline Flow-through peak 1 & 20 & $2.89 \times 10^{11}$ & 86.2 & $3.0 \times 10^{-6.25}$ \\
\hline Flow-through peak 2 & 20 & $5.07 \times 10^{2}$ & N/A & $1.0 \times 10^{-1}$ \\
\hline Ultracentrifugation & 20 & $2.56 \times 10^{11}$ & 85.8 & $4.09 \times 10^{-5}$ \\
\hline
\end{tabular}

Note: ${ }^{\text {a }}$ Virus recovery from each purification stage was calculated based on the total number of virus particles in the sample quantitated by FQ-PCR. 
(a)
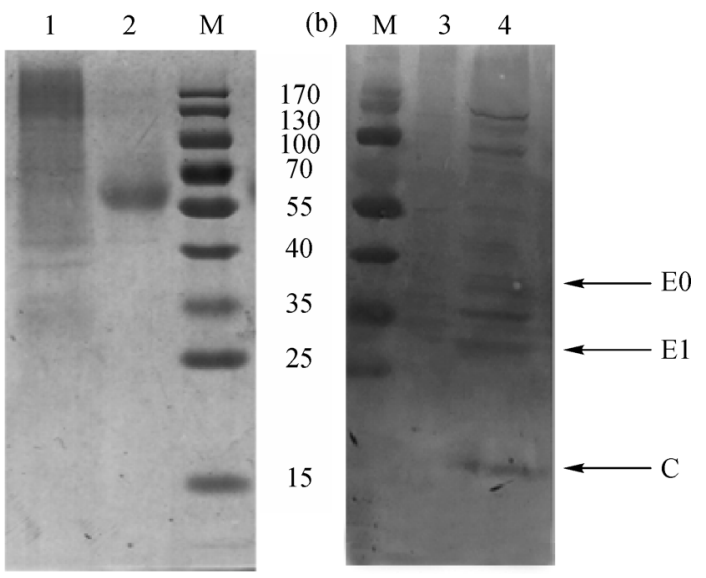

Fig. 3 Analysis of the purified CSFV by TFF-SEC by SDSPAGE (a) and immunoblotting (b). (a) SDS-PAGE: lane 1, peak 1 sample; lane 2, peak 2 sample; M, pre-stained protein molecular marker; (b) immunoblotting: lane 3, peak 2 sample; lane 4, peak 1 sample.

(a)

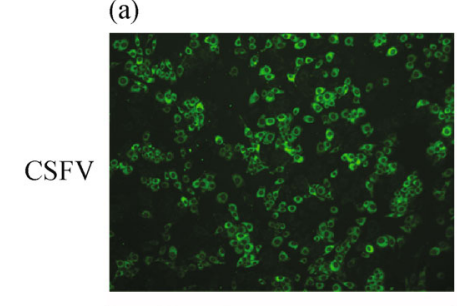

(b)

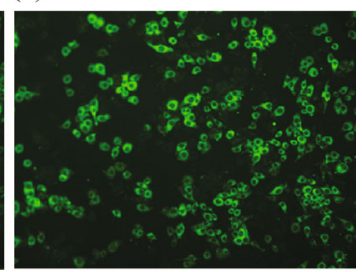

MOCK
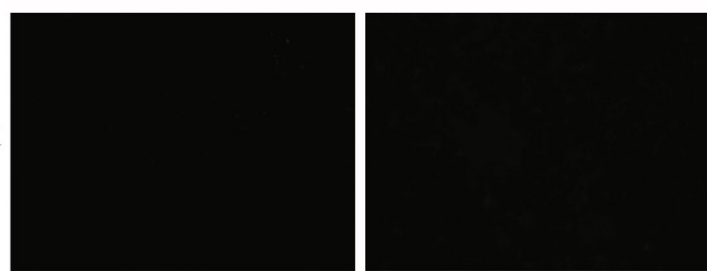

Fig. 4 Immunofluorescence assay. (a) Monolayer of PK-15 cells infected with TFF-SEC-purified CSFV; (b) monolayer of PK-15 cells infected with ultracentrifugation-prepared CSFV. Mockuninfected PK-15 cells were used as negative control.

\subsection{Electron microscopy}

The purification efficiency of the TFF-SEC method was also monitored by TEM. As shown in Fig. 5a, abundant CSFV particles with no visible contaminants were observed, and the particles were roughly spherical with the expected diameter size of 40 to $60 \mathrm{~nm}$. In contrast, CSFV particles purified by ultracentrifugation gave a significant amount of protein aggregates and few visible intact CSFV particles (Fig. 5b).

\subsection{Comparison of antibody responses}

Strip tests revealed that immunization with CSFV prepared by either TFF-SEC or ultracentrifugation produced CSFVspecific antibodies. Although, antibody levels in group A were higher than those from group B $(P<0.05)$ (Fig. 6). Mice immunized with PBS in group $\mathrm{C}$ did not produce any antibody against CSFV.

\section{Discussion}

Virus purification is essential for producing vaccines and understanding physical, chemical, cellular and molecular biology of viruses ${ }^{[21]}$. Methods for virus purification include ultrafiltration ${ }^{[9,12]}$, size exclusion chromatography ${ }^{[7]}$, ion-exchange chromatography ${ }^{[11,22]}$ and affinity chromatography ${ }^{[8,16,23]}$. In this study, a reliable and efficient method that combines tangential-flow ultrafiltration (TFF) and size-exclusion chromatography (SEC) is proposed for CSFV purification. Viral particles are separated from the contaminants on the basis of their sizes. Unlike ultracentrifugation, the methods of TFF and SEC are scalable, which make CSFV purification suitable for commercial production.

TFF-SEC purification of CSFV was compared with ultracentrifugation purification and validated. Ultrafiltration through a $50 \mathrm{kDa}$ NMWL recovered $98.5 \%$ of the

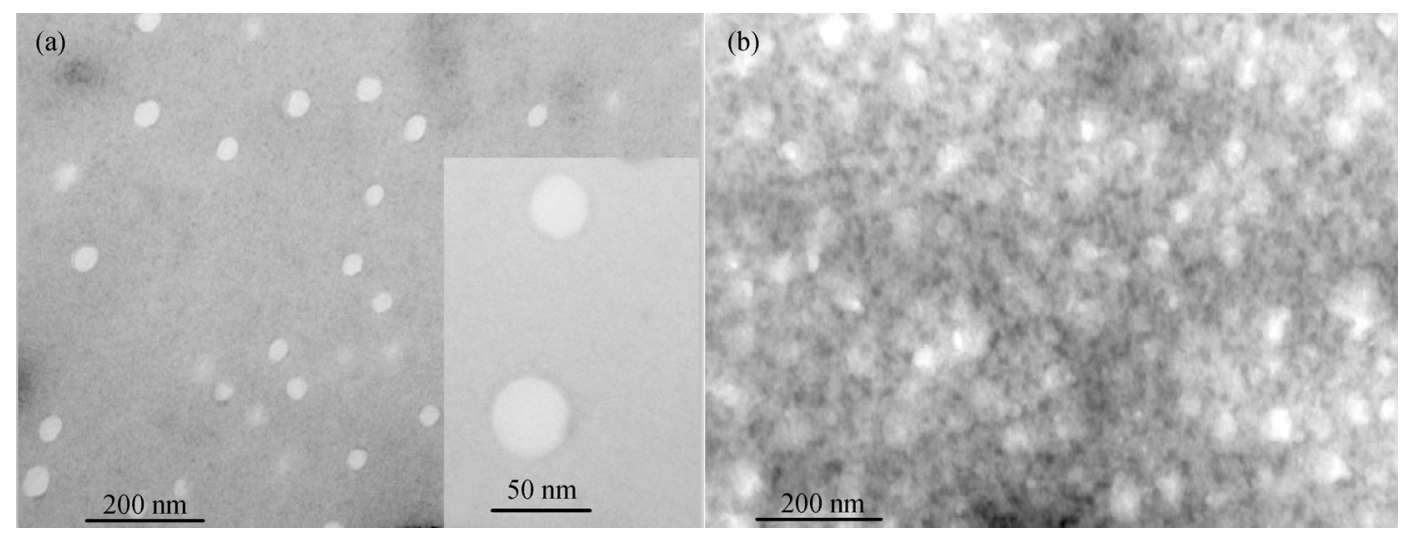

Fig. 5 Electron microscopy of the purified CSFV particles. (a) CSFV particles purified by TFF-SEC are spherical with a diameter of 50 $\mathrm{nm}$; (b) CSFV prepared by ultracentrifugation show few visible intact virions and a significant amount of contaminating substances is evident as the gray background. Primary magnification of $100000 \times$ and $300000 \times$. 


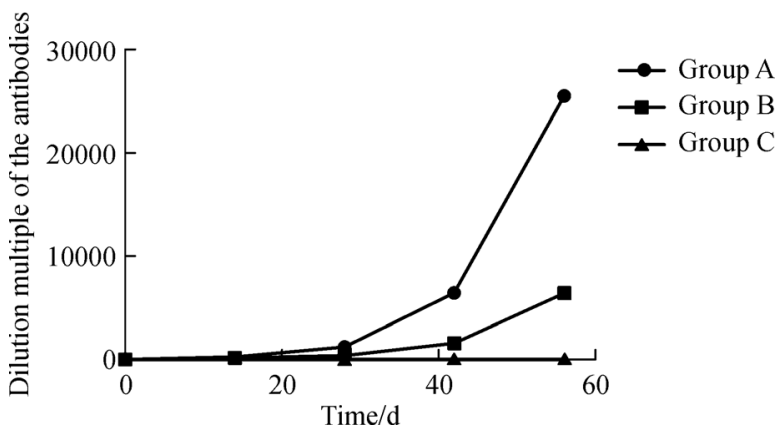

Fig. 6 Comparison of antibody responses. Antibody levels from immunization with CSFV purified from TFF-SEC (group A) and ultracentrifugation (group B) were tested with the strip test and compared. Mice immunized with $\mathrm{PBS}$ in group $\mathrm{C}$ did not produce any antibody against CSFV.

virus particles, and the yield of purified CSFV by TFFSEC was $86.2 \%$. This was higher than that obtained by ultracentrifugation, and the infectivity of TFF-SECpurified CSFV was also higher than ultracentrifugationprepared CSFV. CSFV samples prepared by both methods were biologically active and capable of infecting PK-15 cells, but TFF-SEC method removed much more contaminating proteins inform the culture medium than ultracentrifugation. Electron microscopy revealed the presence of mature CSFV particles with a diameter of $40-60 \mathrm{~nm}$ in TFF-SEC-purified samples, and the characteristic morphology and size of purified CSFV viral particles in this study matched those described previously ${ }^{[24]}$. The antibody levels from immunization with CSFV prepared by the two methods showed significant difference $(P<0.05)$, and the existence of contaminants in ultracentrifugationprepared CSFV may reduce the efficiency of the animal's immune response.

\section{Conclusions}

We developed a reliable and efficient method for the purification of CSFV in this study. The method can be used to obtain pure virus preparations with high infectivity and no evident contamination. To the best of our knowledge, combined purification of CSFV viral particles through TFF and SEC is a novel approach. Such a purification strategy can be easily scaled for large volume production, and will help refine the purification process of enveloped viruses for vaccine production.

Acknowledgements This research was supported by the Special Fund for Agro-scientific Research in the Public Interest (201203039) and China Agriculture Research System (CARS-36).

Compliance with ethics guidelines Ruining Wang, Yubao Zhi, Junqing Guo, Qingmei Li, Li Wang, Jifei Yang, Qianyue Jin, Yinbiao Wang, Yanyan Yang, Guangxu Xing, Songlin Qiao, Mengmeng Zhao, Ruiguang Deng, and Gaiping Zhang declare that they have no conflict of interest or financial conflicts to disclose.
All applicable institutional and national guidelines for the care and use of virus were followed.

\section{References}

1. Horzinek M C. Pestiviruses - taxonomic perspectives. Archives of Virology. 1991, 3(Suppl. 3): 1-5

2. Deng R, Brock K V. Molecular cloning and nucleotide sequence of a pestivirus genome, noncytopathic bovine viral diarrhea virus strain SD-1. Virology, 1992, 191(2): 867-879

3. Thiel H J, Stark R, Weiland E, Rümenapf T, Meyers G. Hog cholera virus: molecular composition of virions from a pestivirus. Journal of Virology, 1991, 65(9): 4705-4712

4. Suradhat S, Damrongwatanapokin S, Thanawongnuwech R. Factors critical for successful vaccination against classical swine fever in endemic areas. Veterinary Microbiology, 2007, 119(1): 1-9

5. Cunliffe H R, Rebers P A. The purification and concentration of hog cholera virus. Canadian Journal of Comparative Medicine, 1968, 32(3): 486-492

6. Laude H. Improved method for the purification of hog cholera virus grown in tissue culture. Archives of Virology, 1977, 54(1-2): 41-51

7. Loa C C, Lin T L, Wu C C, Bryan T A, Thacker H L, Hooper T, Schrader D. Purification of turkey coronavirus by Sephacryl sizeexclusion chromatography. Journal of Virological Methods, 2002, 104(2): 187-194

8. Anderson R, Macdonald I, Corbett T, Whiteway A, Prentice H G. A method for the preparation of highly purified adeno-associated virus using affinity column chromatography, protease digestion and solvent extraction. Journal of Virological Methods, 2000, 85(1-2): 23-34

9. Guo Y, Cheng A, Wang M, Zhou Y. Purification of anatid herpesvirus 1 particles by tangential-flow ultrafiltration and sucrose gradient ultracentrifugation. Journal of Virological Methods, 2009, 161(1): $1-6$

10. Kalbfuss B, Genzel Y, Wolff M, Zimmermann A, Morenweiser R, Reichl U. Harvesting and concentration of human influenza A virus produced in serum-free mammalian cell culture for the production of vaccines. Biotechnology and Bioengineering, 2007, 97(1): 73-85

11. Kalbfuss B, Wolff M, Morenweiser R, Reichl U. Purification of cell culture-derived human influenza A virus by size-exclusion and anion-exchange chromatography. Biotechnology and Bioengineering, 2007, 96(5): 932-944

12. Michel J P, Gingery M, Lavelle L. Efficient purification of bromoviruses by ultrafiltration. Journal of Virological Methods, 2004, 122(2): 195-198

13. Nayak D P, Lehmann S, Reichl U. Downstream processing of MDCK cell-derived equine influenza virus. Journal of Chromatography $B, 2005, \mathbf{8 2 3}(2)$ : 75-81

14. Wickramasinghe S R, Kalbfuß B, Zimmermann A, Thom V, Reichl U. Tangential flow microfiltration and ultrafiltration for human influenza A virus concentration and purification. Biotechnology and Bioengineering, 2005, 92(2): 199-208

15. Transfiguracion J, Jaalouk D E, Ghani K, Galipeau J, Kamen A. Size-exclusion chromatography purification of high-titer vesicular stomatitis virus $\mathrm{G}$ glycoprotein-pseudotyped retrovectors for cell 
and gene therapy applications. Human Gene Therapy, 2003, 14(12): $1139-1153$

16. de las Mercedes Segura M, Kamen A, Trudel P, Garnier A. A novel purification strategy for retrovirus gene therapy vectors using heparin affinity chromatography. Biotechnology and Bioengineering, 2005, 90(4): 391-404

17. Reed L J, Muench H. A simple method for estimating fifty percent endpoints. American Journal of Hygiene, 1938, 27: 493-497

18. Leifer I, Blome S, Beer M, Hoffmann B. Development of a highly sensitive real-time RT-PCR protocol for the detection of Classical swine fever virus independent of the $5^{\prime}$ untranslated region. Journal of Virological Methods, 2011, 171(1): 314-317

19. Li X, Wang L, Shi X, Zhao D, Yang J, Yang S, Zhang G. Development of an immunochromatographic strip for rapid detection of antibodies against classical swine fever virus. Journal of Virological Methods, 2012, 180(1-2): 32-37

20. Matanin B M, Huang Y, Meng X J, Zhang C. Purification of the major envelop protein GP5 of porcine reproductive and respiratory syndrome virus (PRRSV) from native virions. Journal of Virological Methods, 2008, 147(1): 127-135

21. Ali A, Roossinck M J. Rapid and efficient purification of Cowpea chlorotic mottle virus by sucrose cushion ultracentrifugation. Journal of Virological Methods, 2007, 141(1): 84-86

22. Karger A, Bettin B, Granzow H, Mettenleiter T C. Simple and rapid purification of alphaherpesviruses by chromatography on a cation exchange membrane. Journal of Virological Methods, 1998, 70(2): 219-224

23. Opitz L, Salaklang J, Büttner H, Reichl U, Wolff M W. Lectinaffinity chromatography for downstream processing of MDCK cell culture derived human influenza A viruses. Vaccine, 2007, 25(5): 939-947

24. Horzinek M, Reczko E, Petzoldt K. On the morphology of hog cholera virus. Archiv fur die Gesamte Virusforschung, 1967, 21(3): 475-478 